\title{
Influences on the thermal efficiency of energy piles
}

\author{
Francesco Cecinato ${ }^{a,}{ }^{*}$, Fleur A. Loveridge ${ }^{b}$ \\ a University of Trento, Department of Civil, Environmental and Mechanical Engineering, Trento, Italy \\ ${ }^{\mathrm{b}}$ University of Southampton, Faculty of Engineering and the Environment, Southampton, UK
}

\section{A R T I C L E I N F O}

\section{Article history:}

Received 19 August 2014

Received in revised form

21 November 2014

Accepted 1 February 2015

Available online 26 February 2015

\section{Keywords:}

Energy piles

Geothermal

Thermal efficiency

Thermal response test

Numerical modelling

Convection-diffusion

\begin{abstract}
A B S T R A C T
Energy piles have recently emerged as a viable alternative to borehole heat exchangers, but their energy efficiency has so far seen little research. In this work, a finite element numerical model is developed for the accurate 3D analysis of transient diffusive and convective heat exchange phenomena taking place in geothermal structures. The model is validated by reproducing both the outcome of a thermal response test carried out on a test pile, and the average response of the linear heat source analytical solution. Then, the model is employed to carry out a parametric analysis to identify the key factors in maximising the pile energy efficiency. It is shown that the most influential design parameter is the number of pipes, which can be more conveniently increased, within a reasonable range, compared to increasing the pile dimensions. The influence of changing pile length, concrete conductivity, pile diameter and concrete cover are also discussed in light of their energetic implications. Counter to engineering intuition, the fluid flowrate does not emerge as important in energy efficiency, provided it is sufficient to ensure turbulent flow. The model presented in this paper can be easily adapted to the detailed study of other types of geothermal structures.
\end{abstract}

๑) 2015 Elsevier Ltd. All rights reserved.

\section{Introduction}

Increased use of renewable energy is required in the coming decades to contribute to a reduction in global energy use and also a reduction in carbon dioxide emissions. Ground source heat pump systems will make an important contribution to renewable energy as they lead to both energy efficiencies in buildings and are compatible with moving away from fossil fuels as lower carbon sources of electricity become available. However, ground source heat pump systems have a high up front capital cost meaning there is a pay back period of several years before the building owner sees the benefit of the energy efficiencies of the system. Consequently, any means to either reduce the capital cost of systems and/or increase their efficiency will be timely.

All ground source heat pump schemes comprise a series of ground heat exchangers forming a primary circuit and a building heating system forming the secondary circuit. As well as the heat pumps themselves, construction of the ground heat exchangers, where pipes must be cast into the ground, are also a significant

\footnotetext{
* Corresponding author. Tel.: +390461 282585.

E-mail addresses: francesco.cecinato@unitn.it (F. Cecinato), Fleur.Loveridge@ soton.ac.uk (F.A. Loveridge).
}

capital cost. One way to reduce this cost, and also save on embodied energy, is to use the piled foundations of new buildings as the ground heat exchangers (e.g Ref. [32]), so called energy piles. This removes the requirement to make expensive special purpose excavations. In addition, the larger diameter of energy piles tends to mean they can be expected to have a greater energy capacity per drilled metre than other types of ground heat exchanger, such as boreholes [4]. While borehole heat exchangers have been in use and the subject of research for decades (e.g Ref. [29]), energy piles are only now becoming more common (e.g Ref. [1]). Consequently, the energy efficiency of piles used as ground heat exchangers has seen little research compared to other types of ground heat exchangers.

In fact, much energy pile design is currently carried out using methods developed for borehole ground heat exchangers. In such cases it is usually beneficial to install two rather than one U-loops of heat transfer pipes and to separate the up and down legs of the Uloops with spacers to prevent thermal interactions (e.g Ref. [2]). With energy piles there is the scope for inclusions of many more pipes within the pile cross section, but little available guidance as to optimum spacing or arrangements. It is factors like these, along with pile size, thermal properties and heat transfer fluid flowrate that will influence the thermal behaviour and ultimately the energy efficiency of the pile. While some studies of these factors exist, 
there is currently no overarching framework to help engineers make design decisions.

\section{Background}

Initial studies into energy piles were carried out by Brandl [5]. For smaller diameter energy piles he characterised thermal output in terms of Watts per metre length of the pile, but used Watts per square metre for larger diameter piles $(\geq 600 \mathrm{~mm})$ reflecting the expected beneficial effects of larger surface areas of bigger piles. The internal thermal aspects of energy piles are often taken into account by a lumped parameter known as thermal resistance. A low thermal resistance means more efficient thermal transfer to the surrounding ground. As thermal resistance encompasses both geometry and material property effects, it is convenient in many respects, but can mask which of these parameters is most important. Guidance for determining pile thermal resistance can be found in Ref. [27] and [20]. The former publication suggests that larger diameter piles are only more efficient if the opportunity to install more pipes is taken. The latter contains a more detailed study showing the importance of the pile concrete thermal properties and the position of the pipes within the pile. However, the study is limited to two dimensions and therefore does not include the influence of pipe flow condition and the potential for pipe-to-pipe interactions.

Ref. [16] investigated experimentally the importance of the number of heat transfer pipes and their connections. Parallel Uloops were seen to be slightly more efficient than series U-loops and the study also confirmed the potential for greater heat transfer with more pipes and faster fluid flow conditions. It has also been shown that the flow conditions are of greater relative importance when there are only few pipes [4]. Recently there has also been interest in the potential for greater energy efficiency from using spiral coil type heat transfer pipes rather than vertical pipes installed as U-loops (e.g Refs. [24,34]). However, practically spiral coils are rarely installed as they are limited to use in scenarios where the pile reinforcement cage, to which the coils must be fixed, is installed in one piece.

To investigate further how the design of energy piles can be adjusted to increase their energy efficiency this paper presents a numerical sensitivity study covering the key factors that will control the pile thermal behaviour: pile diameter and length, concrete cover, concrete thermal conductivity, number and diameter of installed pipes, fluid flow velocity. Numerical methods are common in ground heat exchanger research (e.g Refs. $[13,33]$ ) and allow consideration of many more configurations that can be addressed in practical experiments. However, most models are produced to consider specific case studies (e.g Refs. $[14,18,28]$ ) and do not take the opportunity to study the important general problem of optimisation guidance for designers. Distinct from previous work this study allows the relative importance of the design key parameters to be compared so that practical recommendations can be made regarding where designers should focus their efforts to increase the energy efficiency of their energy piles scheme. The results of the analysis therefore allow development of an overarching framework for efficient thermal design of energy piles. For simplicity, this study is limited to rotary bored piles with vertical pipes (or Uloops) installed as this is the most common approach globally for equipping energy piles.

\section{Model description}

\subsection{Theoretical background}

The proposed numerical model aims at realistically reproducing the main processes behind the heat transfer phenomenon, taking place in geothermal structures. In this case it is applied to energy piles, but would be equally applicable to other energy geostructures. Three principal components of a geothermal system are identified as the heat exchanger fluid within the pipes, the grout/concrete filling the space between the pipes and the ground, and the soil/rock surrounding the heat exchanger. The corresponding three main heat transfer mechanisms are thermal convection between the fluid and the pipe wall, thermal conduction in the grout/concrete, and thermal conduction in the ground.

The above depicted situation provides a simplified representation of reality where additional thermal phenomena may occur, such as thermal radiation at the soil surface and convective heat transfer in the pore water, when the groundwater is flowing. While the role of radiant heat exchange is generally deemed to be negligible in all but the coarsest of soils [15,26], the potential importance of groundwater convection makes the model realistically applicable to cases of low-permeability, or dry, soils or rocks. However, if the groundwater at a specific site is known to be in static conditions, the model can be also applied to high-permeability water-saturated geologic materials.

A general form of the convection-diffusion equation that applies to the heat exchanger fluid, neglecting the contribution of friction heat dissipated by viscous shear, is

$\dot{T}-\nabla(D \nabla T)+v \nabla T=S$

where $T$ the temperature, $D$ the fluid thermal diffusivity, $v$ the fluid velocity and $S$ the temperature sink term. The first term on the left hand side of Equation (1) represents the time rate of change of temperature, the second term represents heat diffusion in the circulating fluid along the pipe, and the third term is linked to the convective spatial temperature change due to fluid circulation. The sink term represents the convective heat transfer between the fluid and the pipe wall.

By introducing the standard expressions of diffusivity and convective heat transfer, Equation (1) can be expressed in terms of heat flux quantities, as

$\rho_{f} c_{p f} \dot{T}-\nabla\left(\lambda_{f} \nabla T\right)+\dot{m} c_{p f} \nabla T=h \Delta T$

where $\rho_{f}$ and $c_{p f}$ the fluid density and specific heat capacity, $\lambda_{f}$ the fluid thermal conductivity, $\dot{m}=\rho v A$ the mass flowrate, A the pipe cross-sectional area, $h$ the 'film' (or convective heat transfer) coefficient, and $\Delta T=\left(T_{s}-T_{f}\right)$ the temperature difference between the solid interface (pipe wall) and the fluid.

Equation (2) can be simplified for the purposes of our analysis, by assuming that (i) convection due to fluid flow occurs as a quasistatic phenomenon, and (ii) conductive heat transfer along the flow direction can be neglected compared to both the radial heat transfer at the fluid/pipe wall interface and the convective transfer.

The above simplifying hypotheses correspond to neglecting the first two terms of Equation (2), and were shown to yield accurate results for the purposes of vertical ground heat exchangers simulation [7]. It should be remarked that ignoring the first term of Equation (2) implies neglecting temperature variations due to the temperature front propagating along with fluid flow. This may lead to inaccurate modelling of the very early stage of circulation, if a sharp temperature discontinuity is imposed at the inlet pipe, limited to the time span required for the temperature front to reach the outlet (of the order of a few seconds to a few minutes, depending on the flowrate and circuit length). This approximation is acceptable since the typical time span of interest for our simulations is several order of magnitudes larger (a few days). Furthermore, as shown in Section 4, the simulation results obtained 
with this assumption can accurately reproduce temperature field measurements for the full operating time range.

The heat transfer through the pipe wall, concrete/grout and the ground is governed by standard transient heat conduction, derived from Equation (1) as

$\rho_{s} c_{p s} \dot{T}=\nabla\left(\lambda_{s} \nabla T\right)$

where $\rho_{s}, c_{p s}$ and $\lambda_{s}$ are respectively the density, specific heat capacity and thermal conductivity of the considered solid material.

\subsection{Numerical implementation}

The above outlined transient heat convection-diffusion problem applied to energy piles was solved by resorting to the Finite Element Method. The model was implemented following a similar procedure to that outlined by Ref. [7]; employing software ABAQUS to integrate 3D transient conduction through the solids (Equation (3)), complemented by writing bespoke user subroutines to model the convective heat transfer at the fluid/solid interface and the temperature changes in the fluid along the pipe. This corresponds to solving, at a given time step, at each node $k$ along the pipe circuit a simplified and discretised version of Equation (2):

$\Delta T_{\text {flow }, k}=\frac{h_{e}\left(T_{S}-T_{f}\right) S}{\dot{m} c_{p f}}$

where $\Delta T_{\text {flow }, k}=\left(T_{k}-T_{k-1}\right)$ the temperature difference between node $\mathrm{k}$ and the node preceding $k$ in the fluid flow direction, $h_{e}$ an equivalent film coefficient to include the effect of conduction through the pipe wall, $S$ the lateral pipe surface and $T_{S}$ the temperature of concrete adjacent to the pipe.

Bespoke Fortran coding was incorporated into user subroutine FILM to specify, at each node representing the pipe-ground interface, the fluid temperature $T_{f}$ and the equivalent film coefficient $h_{e}$. User subroutine URDFIL was used to access the ABAQUS internal results file, create additional support files to describe the fluid circulation in the U-loops and perform the necessary calculations to solve Equation (4), deducing the fluid temperature $T_{k}$ at all nodes along the pipe at each calculation time step.

The above outlined procedure results in a calculation scheme that performs at each time step, alongside the standard ABAQUS calculation of heat diffusion in the concrete/ground, the necessary convection computations in the following semi-coupled way: (1) calculation via subroutine FILM, at each pipe segment, of the radial heat flux as $\dot{q}_{i}=h_{e i}\left(T_{s i}-T_{f i}\right) / S_{i}$ (where $S_{i}$ the lateral surface of the ith pipe segment); (2) calculation via subroutine URDFIL, at each pipe node, of the fluid temperature change as $\left(T_{k}-T_{k-1}\right)=\dot{q}_{i} S_{l} / \dot{m} c_{p f}$.

To minimise computational time, yet controlling the element aspect ratio and node spacing at key locations to warrant accuracy of heat exchange calculations, the 3D FE mesh was created via manual input in an axisymmetric fashion, consisting of 6-node linear triangular prism and 8-node linear brick diffusive heat transfer elements (Fig. 1). The spacing of the nodes representing the ground was progressively increased towards the outer boundary, while the mesh was refined in the exchanger pipe and surrounding pile areas. The size of the domain was chosen by numerical experimentation to be much larger than the area actually affected by heat transfer, for the time range explored in this study.

Despite the fluid temperature change being calculated with an explicit procedure (Equation (4)), numerical experimentation showed that fairly large integration time steps $\Delta t$ can be adopted (the standard setting for all simulations described below is
$\Delta t=5 \mathrm{~min}$ ), except for cases where the pipe circuit (constituted by several U-pipes connected in series) is particularly long, the flowrate is low and there is a sharp difference between initial ground and inlet fluid temperature. In these cases, the integration time step is reduced during the first $30-60 \mathrm{~min}$ of simulation to minimise numerical instabilities (e.g., for run 5 shown in Table 5 below, $\Delta t$ was gradually incremented from $0.5 \mathrm{~min}$ to $5 \mathrm{~min}$ during the first 50 min of simulation).

A single energy pile was represented in the mesh, with the possibility of selecting the position and number of embedded pipes, as well as the type of hydraulic connection between the loops (in series or in parallel). Significant calculation time can be spared exploiting the symmetry of the problem, i.e. only one half of the domain can be considered, as shown in Fig. 1a. This is possible whenever (i) a single U-pipe loop is installed, or (ii) multiple Uloops connected in parallel are installed, provided that the number of loops is even (i.e. the total number of pipes in the cross section is a multiple of 4 ). The complete domain must be considered whenever several U-loops are connected in series.

As boundary conditions, the inlet fluid temperature is prescribed with the relevant time history via subroutine URDFIL. Natural boundary conditions are adopted for the outer domain bounds. As initial conditions, no heat flux and a unique equilibrium temperature for both the fluid and the concrete/ground are set.

\section{Model validation}

\subsection{Reproduction of TRT field data}

The proposed numerical model was tested by reproducing a multi-stage TRT (thermal response test) carried out in London on a $300 \mathrm{~mm}$ diameter, $26.8 \mathrm{~m}$ length test pile [19]. The pile was equipped with a single U-loop, $32 \mathrm{~mm}$ diameter pipe and was installed through water-saturated, firm to stiff London Clay. During the test the fluid volumetric flowrate and inlet and outlet temperatures were measured at five minute intervals using an electromagnetic flow meter and Iron-Constantan (J type) thermocouples respectively. The flow meter has an accuracy of approximately $1 \%$ at the flowrates used and a repeatability of $\pm 0.2 \%$. Calibration of the thermocouples prior to the test showed accuracy within $0.2{ }^{\circ} \mathrm{C}$. In addition to the fluid measurements, temperatures within the pile concrete were measured at four depths by thermistors associated with vibrating wire strains gauges placed within the pile to help understand the mechanical behaviour of the pile. Temperature measurements from such devices tend to be accurate to around $0.5^{\circ} \mathrm{C}$. The test started with an initial isothermal circulation (stage 1) and then comprised different stages where a heat injection test (stage 2 ) and recovery period (stage 3 ) was followed by a heat extraction test (stage 4 ) and recovery period (stage 5 ) (Fig. 2).

The TRT geometry, including the pipe spacing, was reproduced in detail in the numerical model, referring to half of the domain for symmetry reasons. The physical and thermal properties of the materials involved were taken, wherever possible, from published data $[7,19]$. As an example, the concrete density was set as the average of measured values on tested concrete cubes, $\rho_{c}=2210 \mathrm{~kg} /$ $\mathrm{m}^{3}$ and the soil density was set to $\rho_{g}=1900 \mathrm{~kg} / \mathrm{m}^{3}$ as a reasonable value for firm to stiff London Clay (e.g. see Ref. [3]).

Particular attention was given to the choice of fundamental parameters regulating transient heat diffusion, namely $\lambda_{c}, \lambda_{g}$, thermal conductivities, and $c_{p c}, c_{p g}$, specific heat capacities, of concrete and the ground respectively. Of the two properties, specific heat capacity is rarely considered in practical geothermal studies, as it is peculiar to transient analyses only, while thermal conductivity is frequently measured in the field, since it features in 

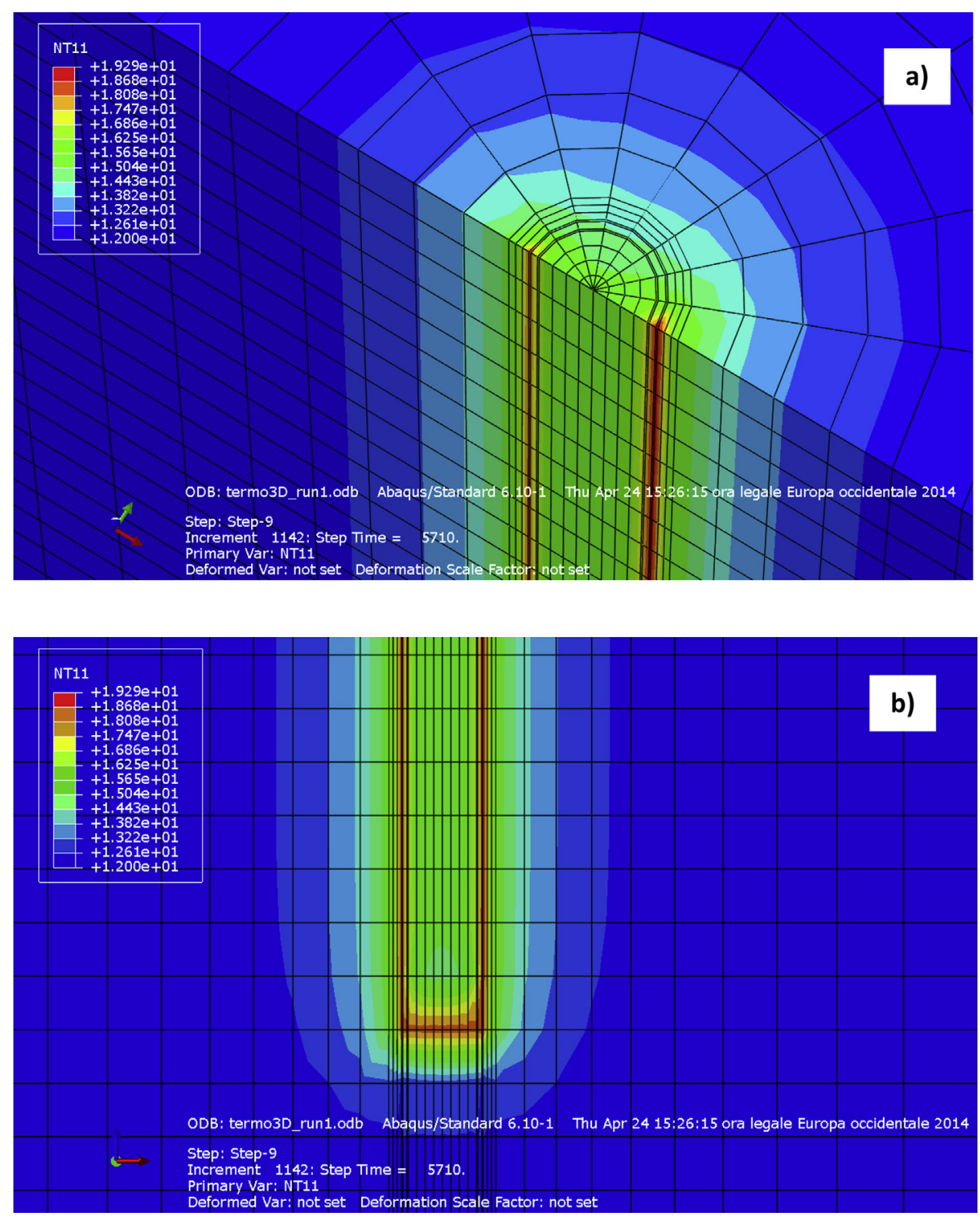

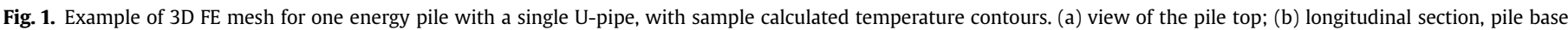
zone. Only a half of the domain is considered for symmetry reasons (the symmetry plane cuts through the two exchanger pipes).

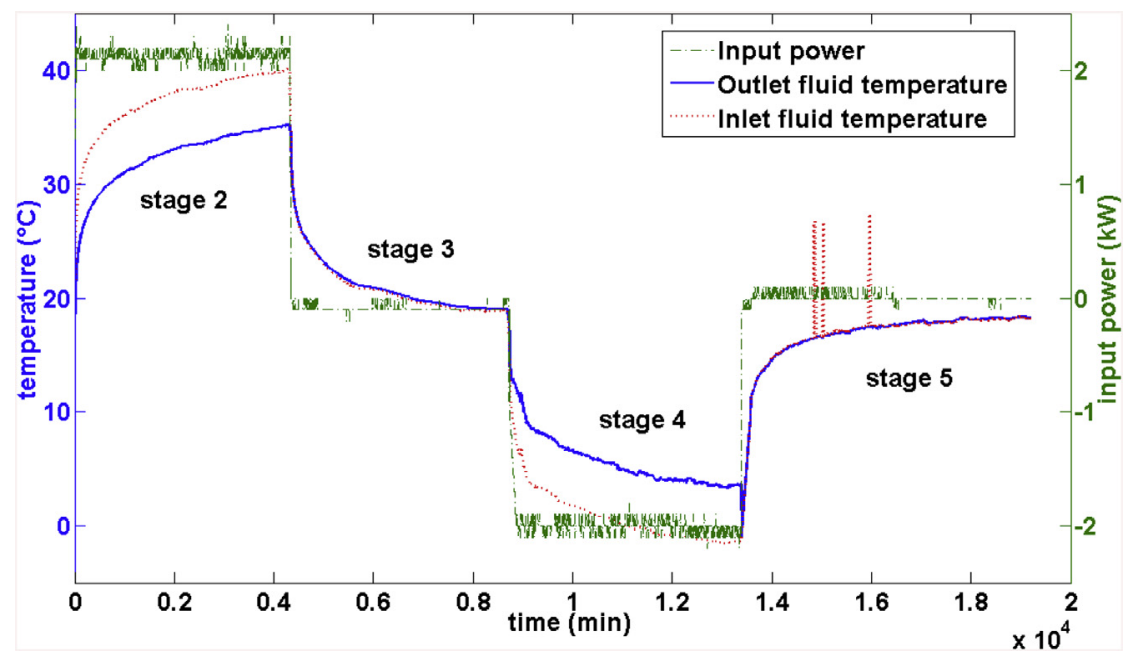

Fig. 2. Inlet and outlet fluid temperature and input power versus time for stages $2-5$ of the London TRT 
Table 1

List of parameters adopted for all materials involved in the verification simulation.

\begin{tabular}{llll}
\hline Materials & Parameters & Values & Units \\
\hline Water/circulating fluid & Density & 1000 & $\mathrm{~kg} / \mathrm{m}^{3}$ \\
& Kinematic viscosity & $1.00 \mathrm{E}-06$ & $\mathrm{~m}^{2} / \mathrm{s}$ \\
& Specific heat capacity & 4200 & $\mathrm{~J} /(\mathrm{kg} \mathrm{K})$ \\
& Mass flowrate & 0.108 & $\mathrm{~kg} / \mathrm{s}$ \\
& Thermal conductivity & 0.6 & $\mathrm{~W} / \mathrm{mK}$ \\
& Prandtl number & 7 & \\
Concrete & Density & 2210 & $\mathrm{~kg} / \mathrm{m}^{3}$ \\
& Specific heat capacity & 1050 & $\mathrm{~J} /(\mathrm{kg} \mathrm{K})$ \\
PE (pipe material) & Thermal conductivity & 2.8 & $\mathrm{~W} / \mathrm{mK}$ \\
Soil & Thermal conductivity & 0.385 & $\mathrm{~W} / \mathrm{mK}$ \\
& Density & 1900 & $\mathrm{~kg} / \mathrm{m}^{3}$ \\
& Specific heat capacity & 1820 & $\mathrm{~J} /(\mathrm{kg} \mathrm{K})$ \\
& Thermal conductivity & 2.3 & $\mathrm{~W} / \mathrm{mK}$ \\
\hline
\end{tabular}

the simplified analytical or empirical steady-state formulae that are routinely used to interpret thermal response tests. For a firstattempt simulation, thermal properties of the concrete (or grout) constituting the solid body of the pile were chosen after [7] as $\lambda_{c}=2.8 \mathrm{~W} / \mathrm{mK}$ and $c_{p c}=1050 \mathrm{~J} / \mathrm{kgK}$. The specific heat capacity of the ground was deduced, assuming the clay to be fully saturated, as $c_{p g}=n c_{p w}+(1-n) c_{p s}$, where $n=0.3$ a reasonable value of porosity, $c_{p w}=4200 \mathrm{~J} / \mathrm{kgK}$ the specific heat capacity of water at ambient temperature and $c_{p s}=800 \mathrm{~J} / \mathrm{kgK}$ the specific heat capacity of soil particles. The soil thermal conductivity, that generally varies depending upon soil type and saturation, was set to $\lambda_{g}=2.3 \mathrm{~W} / \mathrm{mK}$, as obtained by interpreting TRT stages 2 and 3 by means of empirical G-functions [19].

A complete list of parameters adopted for all materials involved in the simulation is reported in Table 1.

As an initial condition, the equilibrium temperature for all materials was set to $17.4{ }^{\circ} \mathrm{C}$, corresponding to the isothermal circulation stage 1 of the test. As a boundary condition, the measured inlet fluid temperature history (Fig. 2) was imposed at the first node of the U-pipe throughout the simulation time (equal to about two weeks for stages 2 through 5).

The simulation results in terms of predicted outlet fluid temperature, compared to the corresponding measured values, are presented in Fig. 3 for TRT stages 2 through 5. It can be observed that the numerical simulation effectively reproduce the field measurements for all stages of the TRT.
To further evaluate the accuracy of the simulation, the RMSE (root mean square error) of the residuals was calculated, resulting in $\mathrm{RMSE}_{2-5}=0.6586$ for stages $2-5$, and $\mathrm{RMSE}_{2-3}=0.2308$, RMSE 4 $5=0.8653$ considering stages $2-3$ and stages $4-5$ respectively. It can be inferred that a somewhat better fit of experimental data is achieved for the first two test stages compared to the second two. This outcome is in line with the findings of Ref. [19] who used analytical and empirical methods to match the TRT output and estimate the ground thermal conductivity, obtaining slightly different back-calculated values of $\lambda_{g}$ for the different test stages.

One of the reasons for the above mentioned reduction of fit as the test progresses is the documented presence, during stage 5, of unexpected spikes in the inlet measured temperature history (Fig. 2). While such spikes were not detected in the outlet temperature measurements (Fig. 2), they did have a noticeable influence in the simulated values of Section 5 (Fig. 3).

To compare our numerical results with those obtained from empirical methods, RMSEs were also calculated considering the 'average fluid temperature' (computed as the average between the measured inlet and simulated outlet temperature), resulting in an improved fit: $\mathrm{RMSE}_{\mathrm{AVG}, 2-5}=0.3293$ for stages $2-5$, and RMSE ${ }_{\mathrm{AVG}, 2-}$ $3=0.1154$, RMSE $\mathrm{AVG}, 4-5=0.4326$ for stages $2-3$ and stages $4-5$ respectively. These values compare favourably with the corresponding RMSE values obtained by the variable power parameter estimation presented by Ref. [19]; suggesting the better accuracy of prediction of a numerical method that accounts for transient diffusion compared to simpler steady-state methods.

To further explore the capabilities of the numerical model, simulated temperature history data from the concrete area were also extracted at selected points along the pile, for direct comparison with available VWSG (vibrating wire strain gauge) temperature measurements during the TRT. Couples of VWSG sensors had been placed at four depth locations, immersed in the concrete and positioned in a symmetric fashion with respect to the pile axis. The sensor position within the pile cross-section view corresponded to a radial distance from the pile centre of $30 \mathrm{~mm}$, and an angular distance from the pipes location of about $90^{\circ}$ (Fig. 4). The availability of reliable VWSG measurements was limited to TRT stage 4 at the time of writing. The rational spacing of the FE 3D mesh allowed accurate selection of the nodes corresponding to the measurement points. A comparison of simulated versus measured concrete temperature at the sample locations of $13.8 \mathrm{~m}$ and $23.8 \mathrm{~m}$

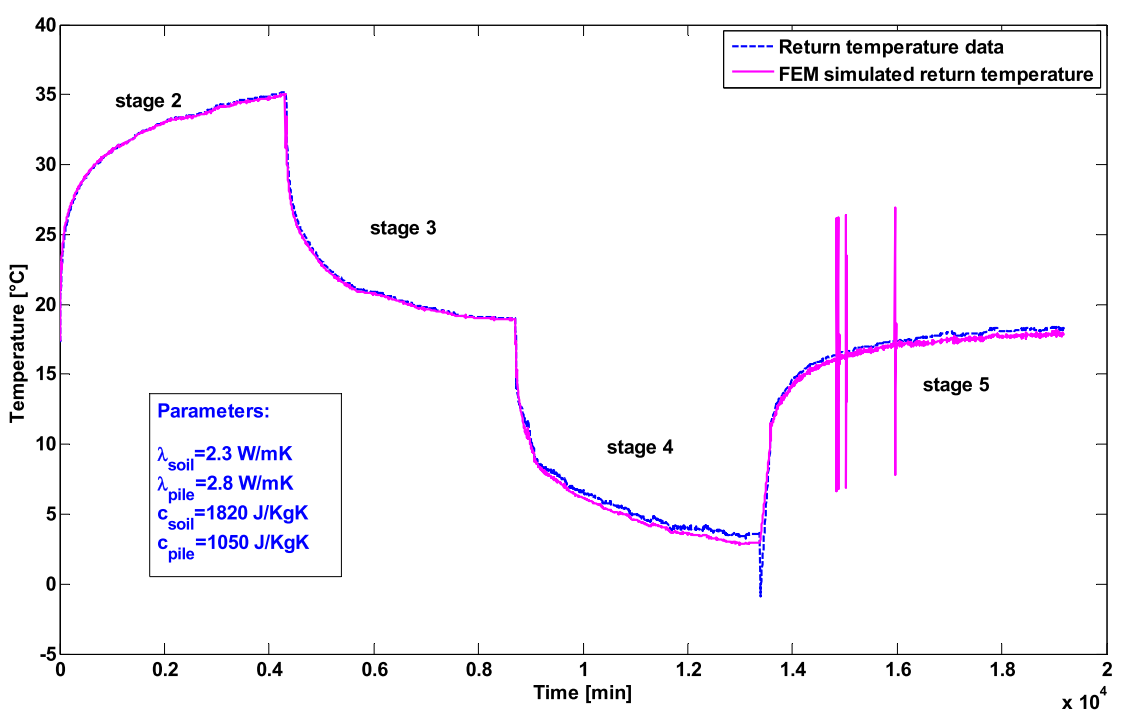

Fig. 3. Predicted outlet fluid temperature (solid line) compared to measured outlet fluid temperature (dashed line) for TRT stages 2 through 5 . 


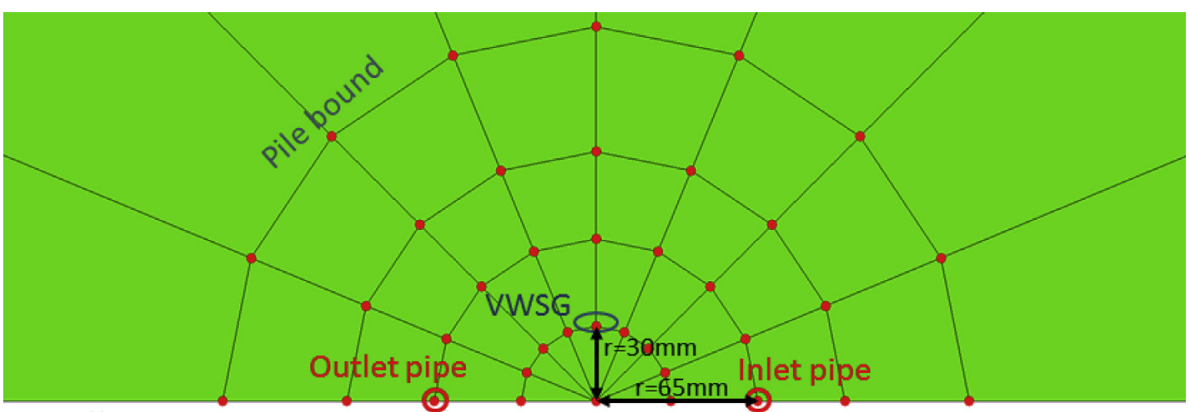

Fig. 4. Schematic of test pile cross-section in the FE model with details about the location of inlet and outlet pipes and VWSG sensors.

of depth, during test stage 4, are shown in Fig. 5 and Fig. 6 respectively. It can be observed that also in this case, numerical predictions can adequately reproduce field measurements. Overall, the agreement between the two curves is less accurate than in the case of fluid temperature. A reason for this might be related to any uncertainty in the precise position of the sensors in an environment when there can be steep temperature gradients.

\subsection{Comparison with analytical model results}

As an additional validation step, the performance of the proposed numerical model was compared to calculations obtained using the infinite line heat source analytical solution.

The analytical solution can be employed to calculate the temperature change in the ground $\Delta T_{g}$ over time $t$ by assuming an infinite line heat source of constant power $q$ per unit depth, as follows [6]:

$\Delta T_{g}=\frac{q}{4 \pi \lambda_{g}} \int_{r^{2} / 4 \alpha_{g} t}^{\infty} \frac{e^{-u}}{u} d u$

where $\lambda_{g}$ and $\alpha_{g}$ are the ground thermal conductivity and diffusivity respectively and $r$ is the radial coordinate.

The numerical code was modified to accommodate the simplifications of the analytical approach. First, the inlet fluid temperature boundary condition was modified. In real TRT tests, although

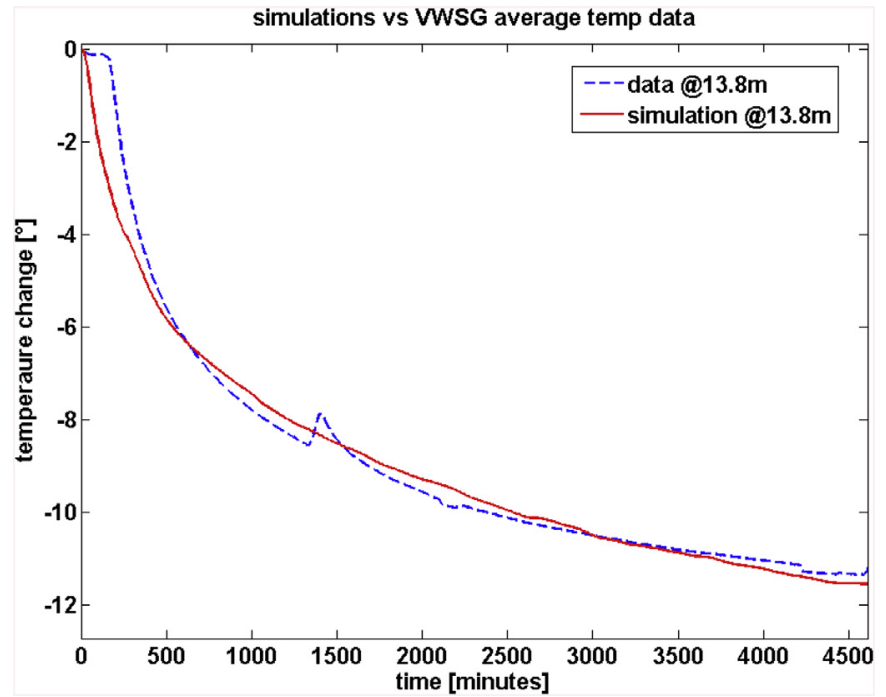

Fig. 5. Comparison of simulated versus measured concrete temperature change history at the sample location of $13.8 \mathrm{~m}$ of depth, during test stage 4 the applied power is nominally constant during each stage of the test, there are actually significant fluctuations with time around the nominal value (e.g. see Fig. 2). Hence, instead of using the TRT inlet temperature history, a synthetic inlet temperature history was dynamically generated during the numerical simulation by means of feedback control, ensuring the maintenance of a constant $q=85.9 \mathrm{~W} / \mathrm{m}$, corresponding to the actual average power applied during stage 2 of the above described TRT. Further, as Equation (5) cannot distinguish between different material properties, the same values of density, thermal conductivity and specific heat capacity were chosen in the numerical code for both concrete and the ground. Finally, to obtain representative values from our 3D output that could be compared to the 1D response of the analytical solution, at any given radius $r$ the average temperature was computed both around the circumference (considering horizontal sections of the $3 \mathrm{D}$ domain) and along the pile depth. As can be seen as an example from the temperature contours shown in Fig. 1, the temperature field is in fact neither uniform around the pile nor along the pile, hence extracting an average value constitutes a strong simplification of the numerical simulation results.

The list of material and geometric parameters used in both types of simulations is reported in Table 2, while the remaining parameters necessary for the numerical simulation are the same as in Table 1. As an example, in Fig. 7 the simulated ground temperature vs time (in log scale) at $r=0.3 \mathrm{~m}$ and $r=0.45 \mathrm{~m}$ is reported for both the numerical and analytical models. Remarkably good agreement

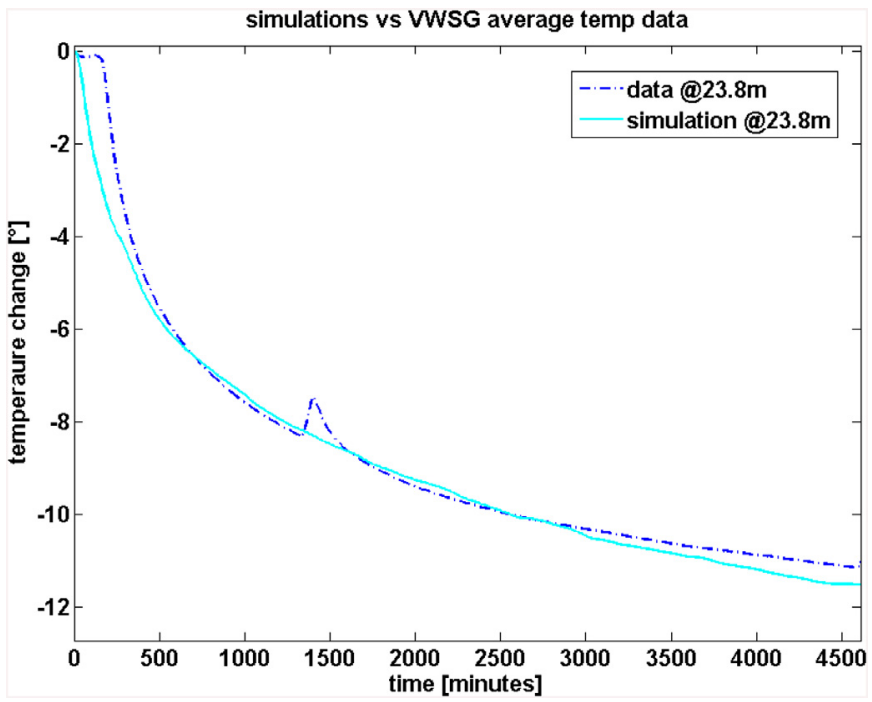

Fig. 6. Comparison of simulated versus measured concrete temperature change history at the sample location of $23.8 \mathrm{~m}$ of depth, during test stage 4 . 
Table 2

Material and geometric parameters used in both numerical and analytical simulations, for comparison between the transient numerical model and the infinite line source solution.

\begin{tabular}{lcl}
\hline Parameters & Values & Units \\
\hline Density & 1900 & $\mathrm{~kg} / \mathrm{m}^{3}$ \\
Specific heat capacity & 2100 & $\mathrm{~J} /(\mathrm{kg} \mathrm{K})$ \\
Thermal conductivity & 2.5 & $\mathrm{~W} / \mathrm{mK}$ \\
Heat flux/unit length & 85.9 & $\mathrm{~W} / \mathrm{mK}$ \\
\hline
\end{tabular}

between the two types of curves can be observed at both locations. A comparatively better agreement is obtained at farther distance from the domain centre, since at smaller values of $r$ the numerical results are realistically more influenced by the inhomogeneity of temperature field due to the closeness of the two branches of Upipe (located at $r=0.065$, Fig. 4). It can be seen that the two types of simulations are most similar in the early-mid range of time, while they tend to diverge at both very early and late times. This is most likely due to the well-known inability of the analytical solution to capture on the one hand initial transient effects, on the other hand three-dimensional effects [21], causing some underestimation of the initial temperature change and overestimation of the long-term temperature change.

\section{Model application: parameters governing energy efficiency}

The 3D numerical model presented above has been shown to provide realistic interpretation of the key aspects related to heat transfer in energy piles. While the significant computational expense (tens of minutes to a few hours with an ordinary laptop) makes the model unsuitable for quick practical design or routine TRT interpretation, it can be fruitfully employed to identify the most important design parameters in maximising energy efficiency. This is done through a number of simulations where each relevant physical or geometrical property of the energy pile is independently varied within realistic ranges.

The energetic efficiency of a geothermal installation can be assessed by looking at the total exchanged energy in a given time. A total simulation time of 4 days was set for all simulations, which could be typical of a larger diameter pile TRT, long enough to explore the bulk of the transient behaviour in most cases, yet short enough to save computational time. The total exchanged power $\dot{q}$ can be calculated from each simulation as

$\dot{q}(t)=\dot{m} c_{p f}\left[T_{\text {in }}(t)-T_{\text {out }}(t)\right]$

where $T_{\text {in }}(t)$ the design inlet temperature history and $T_{\text {out }}(t)$ the simulated outlet temperature history. The inlet temperature can be set as constant over time, after a short ( $5 \mathrm{~min}$ ) initial ramp to avoid possible numerical problems due to the abrupt temperature change. A typical (initial) temperature difference between exchanger fluid and the ground has been set to $8{ }^{\circ} \mathrm{C}$; hence, considering an undisturbed ground temperature of $12^{\circ} \mathrm{C}$ (averagely representative of central Europe) a constant temperature of $20^{\circ} \mathrm{C}$ is set for our simulations. This represents the increasing importance of heat rejection to the ground for cooling buildings. The output variable representing energy efficiency is then computed as

$E_{\text {tot }}=\int_{0}^{t_{f}} \dot{q}(t) d t$

where $t_{f}=5760$ min the total simulation time.

Among all model parameters, the ones that are potentially easier to engineer are chosen for the parametric study: the pile diameter $D_{\text {pile, }}$, the U-pipe external diameter $d_{\text {pipe }}$, the number of pipes in the cross-section $n_{p}$ (Fig. 8), the fluid velocity $v$, the pile length $L$ (reflecting also the pipe circuit length, as the U-pipes are extended until the pile base), the concrete thermal conductivity $\lambda_{c}$ and the concrete cover $c$ (i.e. the distance from the pipe edge to the pile edge, as pipes are attached to the reinforcement cage, see Fig. 8). Model parameters that do not exhibit a high variability, cannot be engineered or are not expected to influence the results with their variation, are kept constant in the parametric study, and are assigned average values (Table 3 ). The ground thermal conductivity is set to $2 \mathrm{~W} / \mathrm{mK}$, which could be considered a mid-range value for geomaterials [2]. The ground specific heat is set to $1600 \mathrm{~J} /$ $\mathrm{kgK}$, which could be considered more typical of soils than the values used for the case study, as it implies a volumetric heat capacity of $3 \mathrm{MJ} / \mathrm{m}^{3} \mathrm{~K}$ [10]. As the ground properties cannot be controlled at any given site this parameter was not part of the sensitivity analysis. However, potentially the concrete properties

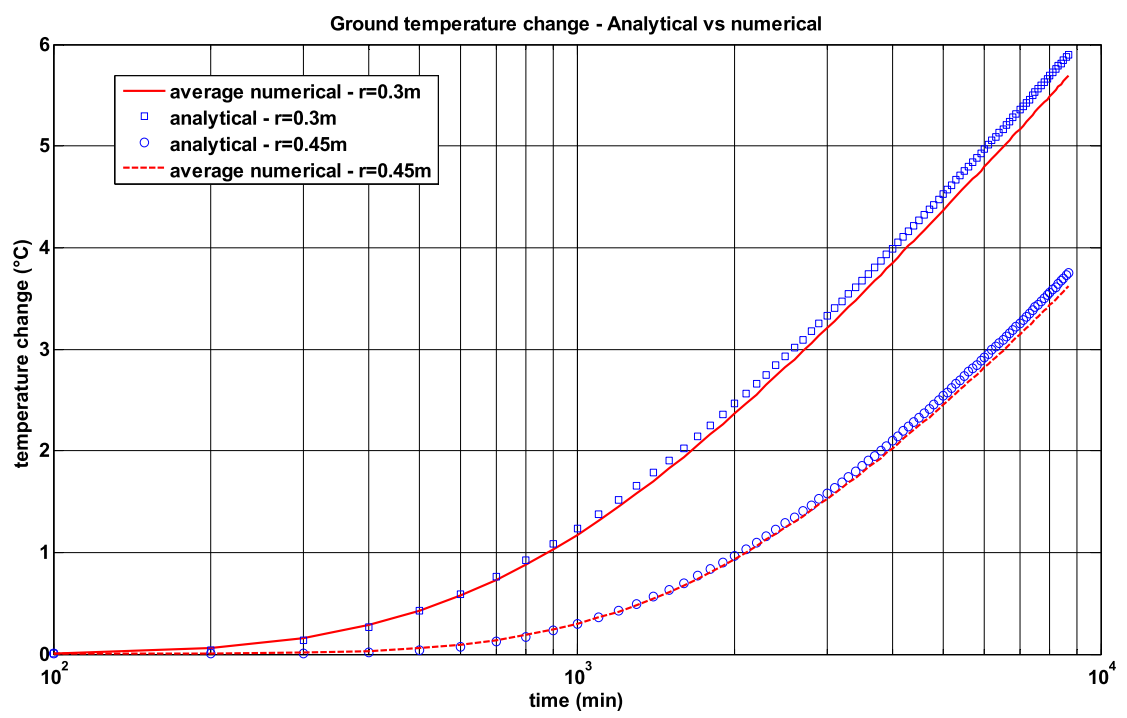

Fig. 7. Simulated ground temperature change for both numerical and analytical simulations at distances from the domain centre of $\mathrm{r}=30 \mathrm{~cm}$ and $\mathrm{r}=45 \mathrm{~cm}$. 


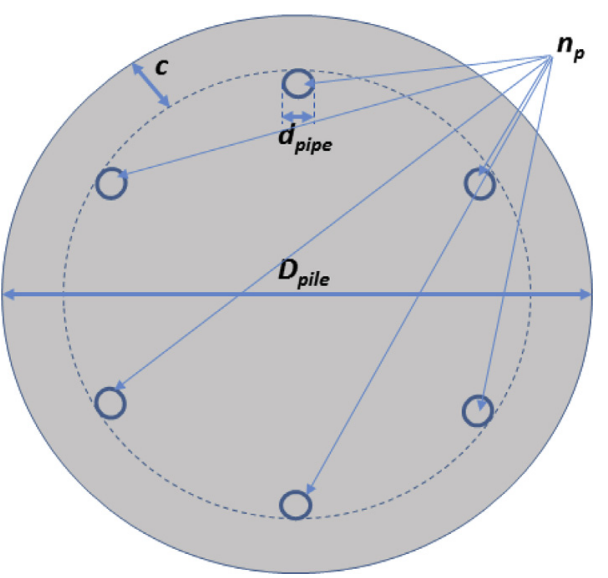

Fig. 8. Schematic of pile geometrical parameters that were chosen for the parametric study.

can be controlled to some extent, and it is known that the ratio of the soil and concrete thermal properties can be important [20].

All simulations are set to reproduce a situation of pipes connected in series, as this is the most common design option in practice. The concrete and the ground are assumed to be fully water-saturated.

\subsection{Choice of parameter range}

After selecting the variables to be examined in the parametric analysis, realistic ranges for them must be established. With the aim of assessing the relative importance of the different properties, it is appropriate to select upper and lower bounds that are not extreme, but representative of typical installations. This ensures the compatibility between the different configurations and avoids parameter interactions that may alter the analysis outcome. We therefore consider $500 \leq D_{\text {pile }} \leq 1000 \mathrm{~mm}, 20 \leq d_{\text {pipe }} \leq 30 \mathrm{~mm}$, and $2 \leq n_{p} \leq 6$ to ensure compatibility with the defined cross-section geometries. A range for fluid velocity of $0.4 \leq v \leq 1.2 \mathrm{~m} / \mathrm{s}$ is chosen to warrant turbulent flow (Reynolds number $R e>8000$ ) whilst not becoming unrealistically large. Pile length is assigned the range $15 \leq L \leq 25 \mathrm{~m}$, which is considered to provide a realistic range of length to diameter ratios (15-50). Saturated concrete thermal conductivity is taken in the range $1.5 \leq \lambda_{c} \leq 3 \mathrm{~W} / \mathrm{mK}$, in line with literature findings (e.g. Ref. [23]). Finally, since this study is concentrated on rotary bored piles, concrete cover range is limited to $50 \leq c \leq 75 \mathrm{~mm}$. Hence, the present analysis is not relevant to CFA (Continuous Flight Auger) piles, where the U-pipes are typically installed separately from the reinforcement, closer to the pile centre (i.e. with much larger $c$ ) to allow full-length installation of heat exchangers.

\subsection{Parametric analysis design}

The aim of the parametric analysis is to run one simulation for each possible combination of the selected parameters, and analyse

Table 3

Model parameter values that are kept constant in the parametric study.

\begin{tabular}{lcl}
\hline Parameters & Values & Units \\
\hline Soil th. conductivity & 2 & $\mathrm{~W} / \mathrm{mK}$ \\
Initial soil temperature & 12 & ${ }^{\circ} \mathrm{C}$ \\
Ground spec. heat & 1600 & $\mathrm{~J} /(\mathrm{kg} \mathrm{K})$ \\
Concrete spec. heat & 1000 & $\mathrm{~J} /(\mathrm{kg} \mathrm{K})$ \\
Soil density & 1900 & $\mathrm{~kg} / \mathrm{m}^{3}$ \\
Concrete density & 2210 & $\mathrm{~kg} / \mathrm{m}^{3}$ \\
\hline
\end{tabular}

Table 4

Selected levels of parameters featuring in the parametric analysis.

\begin{tabular}{llccl}
\hline & Parameter & Lower bound & Upper bound & Units \\
\hline 1 & Pile diameter & 500 & 1000 & $\mathrm{~mm}$ \\
2 & Pipe diameter & 20 & 30 & $\mathrm{~mm}$ \\
3 & No. of pipes & 2 & 6 & \\
4 & Fluid velocity & 0.2 & 1.2 & $\mathrm{~m} / \mathrm{s}$ \\
5 & Pile length & 15 & 25 & $\mathrm{~m}$ \\
6 & Concrete thermal conductivity & 1.5 & 3 & $\mathrm{~W} / \mathrm{mK}$ \\
7 & Concrete cover & 50 & 75 & $\mathrm{~mm}$ \\
\hline
\end{tabular}

the results to determine which factors are most influential in maximising the energy efficiency. The set of values (levels) that each parameter can assume must be defined. For a general, timeefficient analysis, it is sufficient to select two levels for each parameter, namely the upper-bound and the lower-bound values. This choice is justified by the likelihood that the parameters investigated will have a more quantifiable effect in the results when they are set to an extreme value. The seven parameters discussed above are summarised in Table 4, along with the two selected levels.

The parametric study was set up using the concepts of Experimental Design, a branch of Engineering Statistics that deals with deliberately changing one or more variables (the selected parameters) in a process (the simulation of geothermal operation), in order to observe the effect that the changes have on a response variable (the calculated total exchanged energy). Among the available types of experimental design, the one that was found to best suit the problem at hand due to its robustness, simplicity and adaptability to engineering problems, is the Taguchi method (e.g., $[9,25,30])$. With the current settings of seven parameters and two levels (Table 4), a Taguchi analysis will need only 8 simulations (experiments) to be completed, followed by some basic statistical analysis of the results. By contrast, with the 'full factorial' method (i.e. running one simulation for each one of the possible combinations of parameters) the number of simulations needed would be $2^{7}=128$.

A fundamental step in Taguchi analysis is the definition of a suitable 'orthogonal array', i.e., a 2-dimensional matrix defining the variable settings for each of the experiments needed. Each row of the matrix contains the list of settings for all parameters in one experiment. Each column corresponds to one of the variables, and contains all the values that this variable will be assigned during the experiments. The essential property of the orthogonal array is 'statistical independence': not only within each column an equal number of occurrences for each level is present, but also the columns are mutually orthogonal, i.e. for each level within one column, each level within any other column will occur an equal number of times as well. A given parameter has a strong impact on the output variable if the results associated with one of its levels are very different from the results associated with another one of its levels. Since, due to orthogonality, the levels of all other parameters occur an equal number of times for each level of this given parameter, their effect will be cancelled out in the computation of the given parameter's effect. The estimation of the effect of any one particular parameter will then tend to be accurate and reproducible [25].

For the above described 7-parameter, 2-level Taguchi analysis, the conventional orthogonal array " $L 8$ " is readily available in the literature (e.g. Ref. [25]), and can be filled in with the factors' settings of Table 4 to finalise the parametric study design. The resulting array is shown in Table 5, where a column has been added at the extreme right to specify the output of the simulations for each row, i.e., the calculated total exchanged energy (Equation (7)). 
Table 5

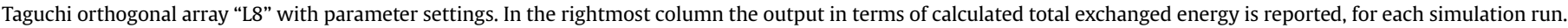

\begin{tabular}{|c|c|c|c|c|c|c|c|c|}
\hline \multirow[t]{2}{*}{ Run\# } & \multirow{2}{*}{$\frac{\text { Pile dia }}{\mathrm{mm}}$} & \multirow{2}{*}{$\frac{\text { PIPE dia }}{\mathrm{mm}}$} & \multirow[t]{2}{*}{ No. pipes } & \multirow{2}{*}{$\frac{\text { Fluid velocity }}{\mathrm{m} / \mathrm{s}}$} & \multirow{2}{*}{$\frac{\text { Pile length }}{\mathrm{m}}$} & \multirow{2}{*}{$\frac{\text { Concrete conductivity }}{\mathrm{W} / \mathrm{mK}}$} & \multirow{2}{*}{$\frac{\text { Concrete cover }}{\mathrm{mm}}$} & \multirow{2}{*}{$\frac{\text { Response }}{\mathrm{MJ}}$} \\
\hline & & & & & & & & \\
\hline 1 & 500 & 20 & 2 & 0.4 & 15 & 1.5 & 50 & $1.54 \mathrm{E}+02$ \\
\hline 2 & 500 & 20 & 2 & 1.2 & 25 & 3 & 75 & $3.73 \mathrm{E}+02$ \\
\hline 3 & 500 & 30 & 6 & 0.4 & 15 & 3 & 75 & $3.30 \mathrm{E}+02$ \\
\hline 4 & 500 & 30 & 6 & 1.2 & 25 & 1.5 & 50 & $4.90 \mathrm{E}+02$ \\
\hline 5 & 1000 & 20 & 6 & 0.4 & 25 & 1.5 & 75 & $5.22 \mathrm{E}+02$ \\
\hline 6 & 1000 & 20 & 6 & 1.2 & 15 & 3 & 50 & $5.52 \mathrm{E}+02$ \\
\hline 7 & 1000 & 30 & 2 & 0.4 & 25 & 3 & 50 & $4.59 \mathrm{E}+02$ \\
\hline 8 & 1000 & 30 & 2 & 1.2 & 15 & 1.5 & 75 & $1.45 \mathrm{E}+02$ \\
\hline Confirmation & 1000 & 20 & 6 & 1.2 & 25 & 3 & 50 & $8.53 E+02$ \\
\hline
\end{tabular}

These rather diverse energy values constitute the 'raw data' of the Taguchi parametric study, to which some statistical post-processing needs to be applied in order to extract meaningful results. This is done in the next Section.

\section{Parametric analysis results}

To determine the combination of factors affecting the target variable the most, the Energy output values of Table 5 were interpreted with a level average analysis [25], consisting of (1) calculating the average simulation result for each level of each factor, (2) quantifying the effect of each factor by taking the absolute difference between the highest and lowest average results and (3) identifying the strong effects, by ranking the factors from the largest to the smallest absolute difference. Results are summarised in the response table (Table 6).

Due to the statistical nature of this type of analyses, the influence of the bottom-ranked parameters cannot be assessed with confidence [25], hence attention will be hereby given to the top-five properties, namely (1) the number of pipes $n_{p}$, (2) the pile length $L$, (3) the concrete thermal conductivity $\lambda_{c}$, (4) the pile diameter $D_{\text {pile, }}$, (5) the concrete cover $c$. It can be seen from Table 6 that energy efficiency is maximised with large values of parameters (1)-(4) and low values of parameter (5).

As a statistical validation of level average analysis, a reliability check $[8,25]$ can be performed, consisting of calculating an estimate of the predicted response with optimal parameter settings and comparing it with a confirmation run based on the most influential settings of the involved parameters (bottom line of Table 5). The confirmation run, consistently, resulted in the single largest energy efficiency $\left(E_{\text {tot }}=8.5 \mathrm{MJ}\right)$, and was corroborated in magnitude by the estimated predicted response $\left(E_{\text {tot }}=7.2 \mathrm{MJ}\right)$.

The calculated outlet fluid temperature curves for all runs of Table 5, including the confirmation run, are reported in Fig. 9, while the corresponding calculated exchanged power curves (whose subtended areas correspond to the total energy exchanged) are reported in Fig. 10. In both figures, time is reported in logarithmic scale, to better appreciate visually the initial parts of the curves. It can be seen that parameter settings achieving a higher level of exchanged power do not in general correspond to those causing a lower outlet temperature (i.e. a higher difference between inlet and outlet temperature). In fact, by virtue of Equation (6) the exchanged power is proportional, in addition to the temperature difference, also to the mass flowrate, which is an increasing function of flow velocity and pipe diameter. For example, it can be seen that run \#5 has the greatest temperature difference through the simulations (Fig. 9), but it also has a low flow velocity meaning that it does not always correspond to the maximum available power (Fig. 10). It can also be observed that the duration of the transient period, and the shape of the curves at early stages are fundamental in determining the overall temperature difference and exchanged power, thus confirming the appropriateness of a 3D numerical model accounting for transient conduction to investigate energy efficiency. The initial part of the transient behaviour relates to the ramp up of the applied temperature difference. All runs reach a peak value of power (Fig. 10), which then decreases with time as the corresponding temperature difference to the ground reduces (Fig. 9). However, different parameters are observed to have different timescales for transient effects. For example, run \#4 has initially the highest power available. This is likely to reflect the large number of pipes in the cross section, the pile length and high flowrates used. The smaller pile diameter also means that this run is accessing the higher conductivity ground more quickly. However, later in the analysis period, the power available is overtaken by other runs where the pile diameter is larger and the concrete conductivity is also larger.

\section{Discussion}

The best scenario for energy efficiency of a geothermal rotarybored pile is represented by the parameter combination chosen for the confirmation run (bottom line of Table 5), as is evident in Fig. 10. The most important parameter is the number of pipes $n_{p}$, followed by the pile length $L$. This outcome suggests that, all other things being equal, the total amount of pipe surface available for convective heat exchange is fundamental. The 2D cross-sectional configuration of pipes (reflected by $n_{p}$ ) has the largest influence, but also the longitudinal dimension (reflected by $L$ ) appears very important. This is not surprising as heat exchange capacity is often expressed in terms of power per drilled depth. However, it is

Table 6

Response table for the parametric analysis, showing in the bottom line the ranking of importance of parameters, from the strongest to the weakest effect.

\begin{tabular}{|c|c|c|c|c|c|c|c|}
\hline \multicolumn{8}{|c|}{ Response table (total exchanged energy in 4 days, $\mathrm{MJ}$ ) } \\
\hline Level/parameter & Pile dia & Pipe dia & No. pipes & Fluid velocity & Pile length & Concrete conductivity & Concrete cover \\
\hline Min & 336.82 & 400.30 & 282.63 & 366.13 & 295.06 & 327.61 & 413.56 \\
\hline Max & 419.25 & 355.77 & 473.43 & 389.94 & 461.01 & 428.45 & 342.50 \\
\hline Effect of parameter & 82.43 & 44.53 & 190.80 & 23.81 & 165.95 & 100.84 & 71.06 \\
\hline Ranking & 4 & 6 & 1 & 7 & 2 & 3 & 5 \\
\hline
\end{tabular}




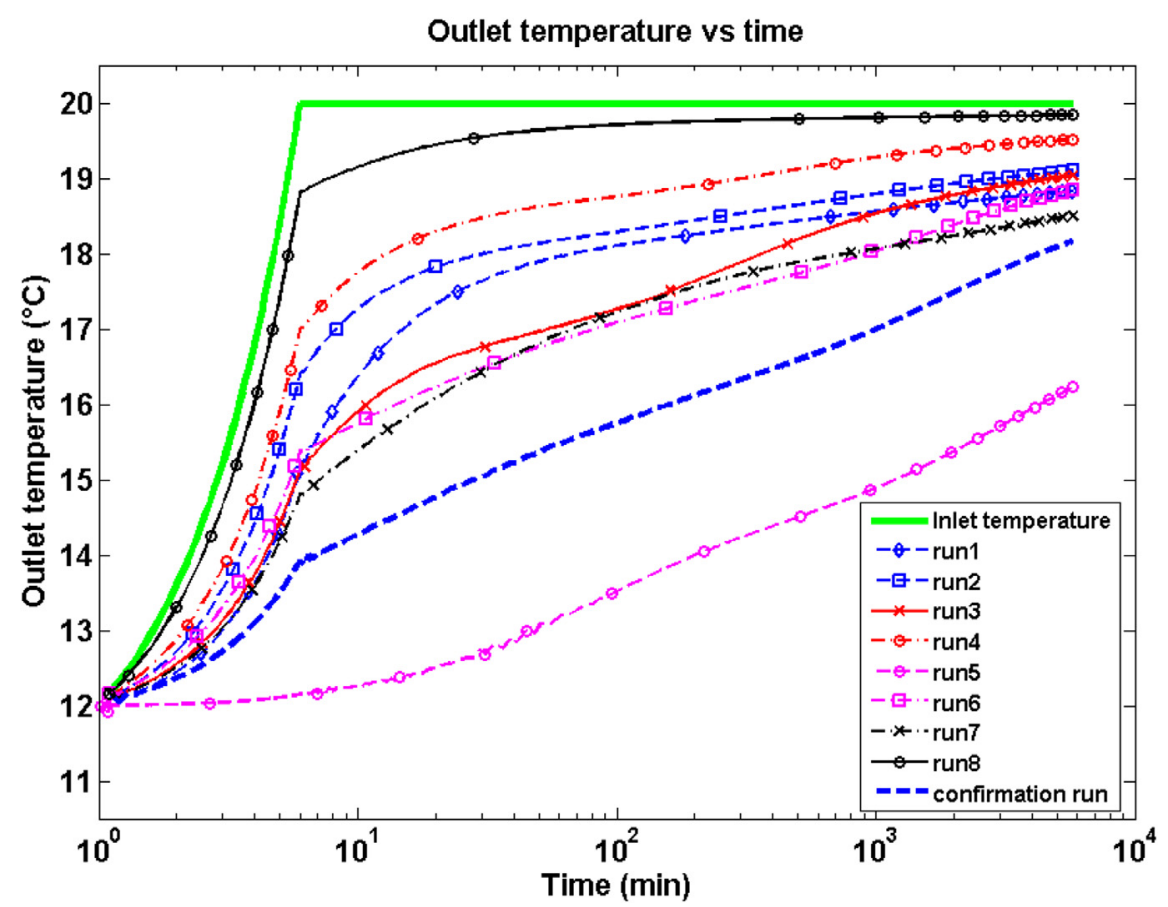

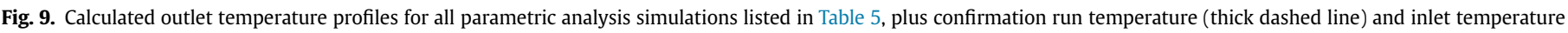
(thick solid line) profiles. Time is shown in logarithmic scale.

easier, in practice, to decide the number of pipes independently of structural/geotechnical design, compared to the pile length, which in contrast to borehole type heat exchangers is rarely increased just to provide additional energy supply. Parameter $n_{p}$ is expected to be limited on the one hand by geometrical constraints (there must be sufficient space to accommodate a number of pipes in the pile section, depending on the pile diameter and concrete cover), and on the other hand by possible pipe-to-pipe thermal interactions. Such interactions are common with borehole heat exchangers where the pipes are, by necessity of the small drilled diameter, closer together. It is well known that for a given number of pipes, ensuring separation of the pipes in this environment will

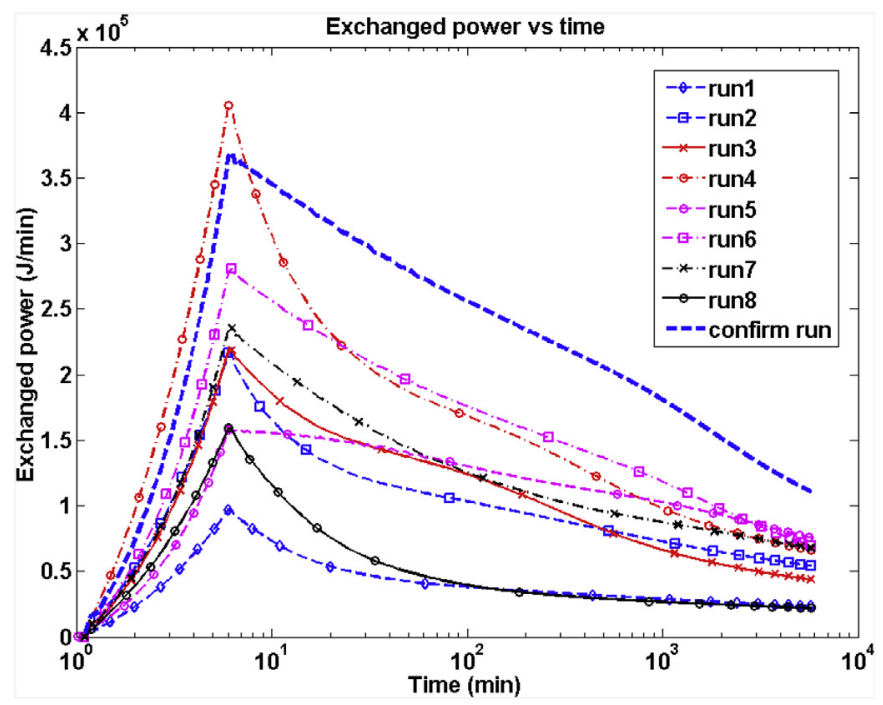

Fig. 10. Calculated exchanged power profiles for all parametric analysis simulations listed in Table 5, plus exchanged power profile for the confirmation run (thick dashed line). Time is shown in logarithmic scale. help maximise energy output by reducing the interaction potential [12]. In addition, it is also known that the benefit from increasing the number of pipes within an energy pile is non-linear and that there will be diminishing returns as more and more pipes are added [20]. This has been further examined by running additional simulations representing a $1000 \mathrm{~mm}$ diameter pile where only parameter $n_{p}$ has been varied, all other things being equal. In particular, the same settings as in run \#6 of Table 5 were kept unchanged for a total of six simulations except for the number of pipes (connected in series), which was set to $2,4,6,8,12$ and 18 . The results of this sensitivity analysis are reported in Fig. 11, where the total exchanged energy $E_{\text {tot }}$ in 4 days is reported as a function of the number of pipes. It can be noticed that at large $n_{p}$ values the curve tends towards horizontal, representing a limit to energy efficiency, demonstrating that a marked nonlinearity exists between $n_{p}$ and $E_{\text {tot. }}$. These diminishing returns can be illustrated with the approximate two thirds increase in exchanged energy when the number of pipes is doubled from two to four. However, doubling $n_{p}$ from 6 to 12 fields an increase in exchanged energy of only one quarter. In Fig. 12, an example of temperature contour lines for each of the $n_{p}$ configurations discussed above is shown at cross-sections of the pile area taken roughly at mid-height of the pile, after 4 days of heat injection. It can be noticed that a larger $n_{p}$ implies a more symmetric distribution of temperature in the domain cross section, and more homogeneous heating of the pile core.

The thermal conductivity of concrete comes third in the ranking of parameter importance. Although this is an expected outcome, since $\lambda_{c}$ is known to play an important role in determining the concrete thermal resistance [20], it cannot be so readily engineered. While concrete conductivity mainly depends on the aggregate lithology [31] and this could potentially be specified by the designer, in practice aggregate types are mostly determined by the locally available materials. However, additives and cement replacement products can reduce concrete conductivity (e.g. Ref. [11]) and these products could be limited by specification. 


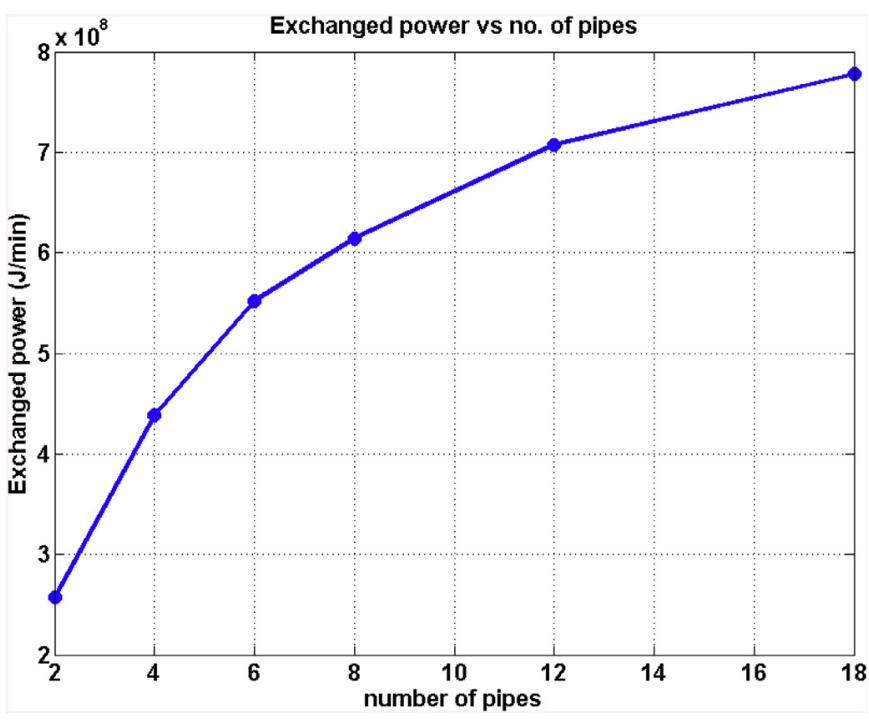

Fig. 11. Total exchanged energy in 4 days as a function of the number of pipes, for a $1000 \mathrm{~mm}$ diameter and $15 \mathrm{~m}$ length pile (configuration of run \#6 in Table 5).

The pile diameter has a comparatively intermediate influence, but it is significant to observe that larger diameters improve the energy efficiency. All else being equal, larger pile diameters allow larger pipe spacing. This can be observed in Fig. 13 and Fig. 14, where temperature contours on a cross-section along the pile are shown for run \#4 and run \#6 of Table 5 respectively, at the same time instant $(t=590 \mathrm{~min})$ during the simulation. For the smaller diameter pile, quicker heating of the pile core occurs with associated energy efficiency reduction. However, this effect is very much secondary compared to the number of pipes installed, and in fact previous studies $[20,27]$ suggest that there is only minimal benefit from a larger pile diameter as long as the same number of pipes is installed. It should also be observed that larger diameter piles have the additional benefit of being capable of being equipped with a greater number of pipes which is clearly beneficial before the spacing reduces so as to decrease efficiency.

The influence of concrete cover is smaller but significant, causing as expected better energy efficiency for smaller values of $c$ (reducing the concrete thermal resistance), which enables pipes to be spaced further apart and also closer to the ground. It should also be noted that recent research has suggested that there is no reduction in protection to the steel reinforcement by installing the pipe loops within the specified minimum concrete cover zone [17] which should help to place the pipes as close to the ground as possible. This parameter is expected to play a more significant role in the energy efficiency of CFA piles, which are not treated in this work.

Among the bottom-ranked parameters, it may appear somewhat surprising to find that the fluid velocity, directly proportional to the volumetric flowrate, has a comparatively negligible influence in the pile's energy efficiency. In fact, empirical guidelines on geothermal design often prescribe a large volumetric flowrate, for better heat exchange efficiency. However, this is mainly aimed at achieving large enough Reynolds numbers (>4000-5000) to achieve turbulent flow in the pipes. In our analysis, the range of $v$ chosen (Section 5.5) always gave $R e>8000$, hence always providing fully turbulent flow. On the other hand, it follows from Equation (4), by substituting the Dittus-Boelter correlation [22] for the convective coefficient and the expression of Reynolds number
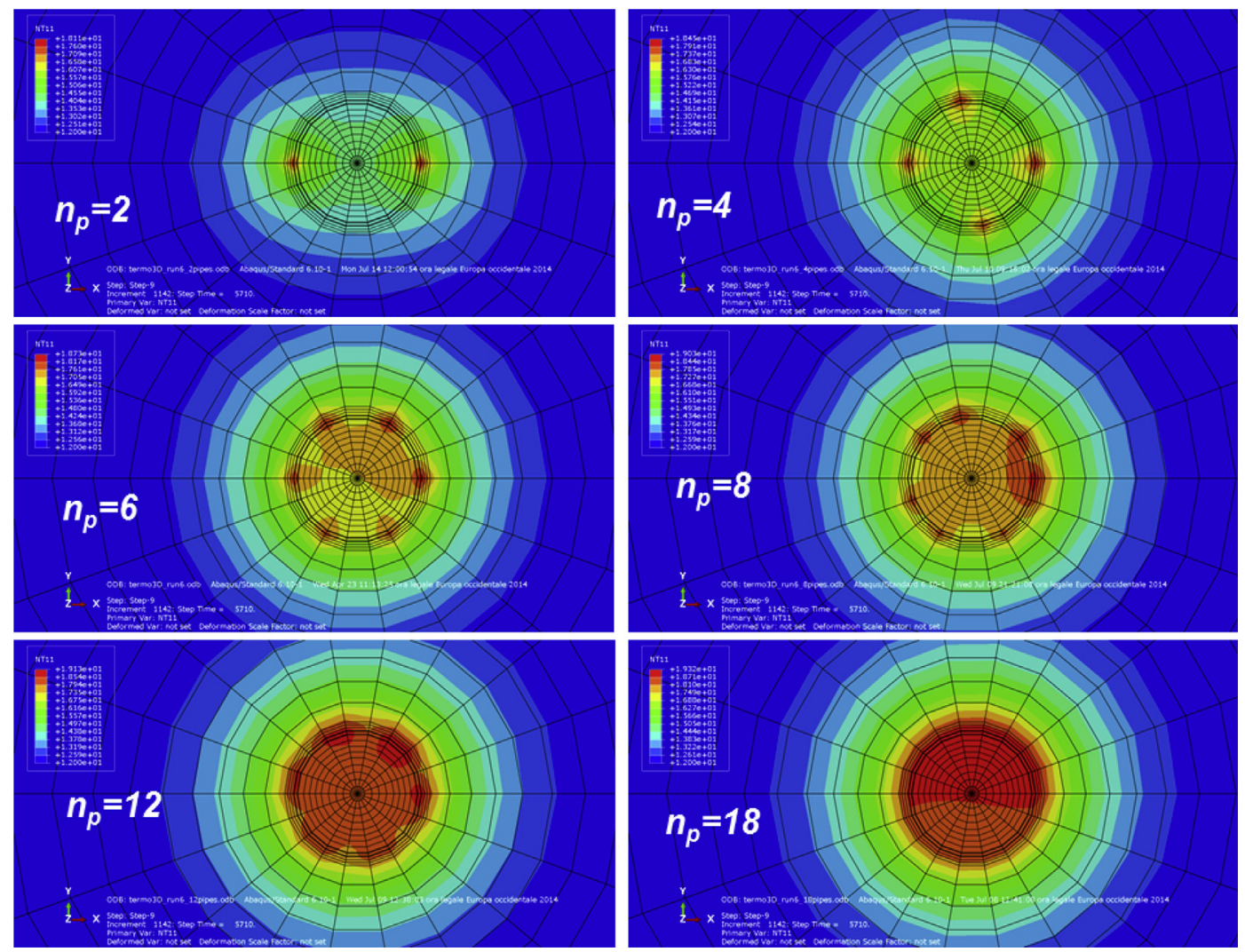

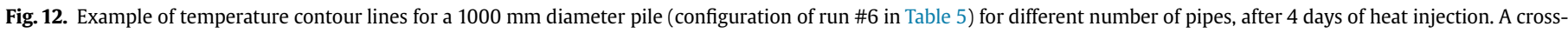
sections of the pile area taken roughly at mid-height of the pile is shown. 


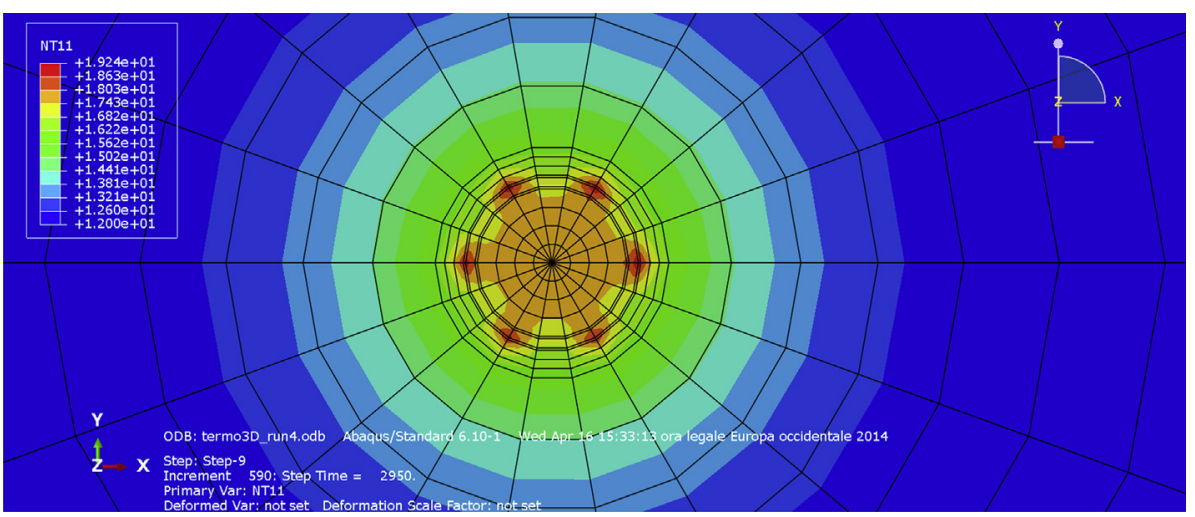

Fig. 13. Temperature contours on a cross-section along a $500 \mathrm{~mm}$ diameter pile for run $\# 4$ of Table 5 , at the time instant $\mathrm{t}=590 \mathrm{~min}$ during the simulation.

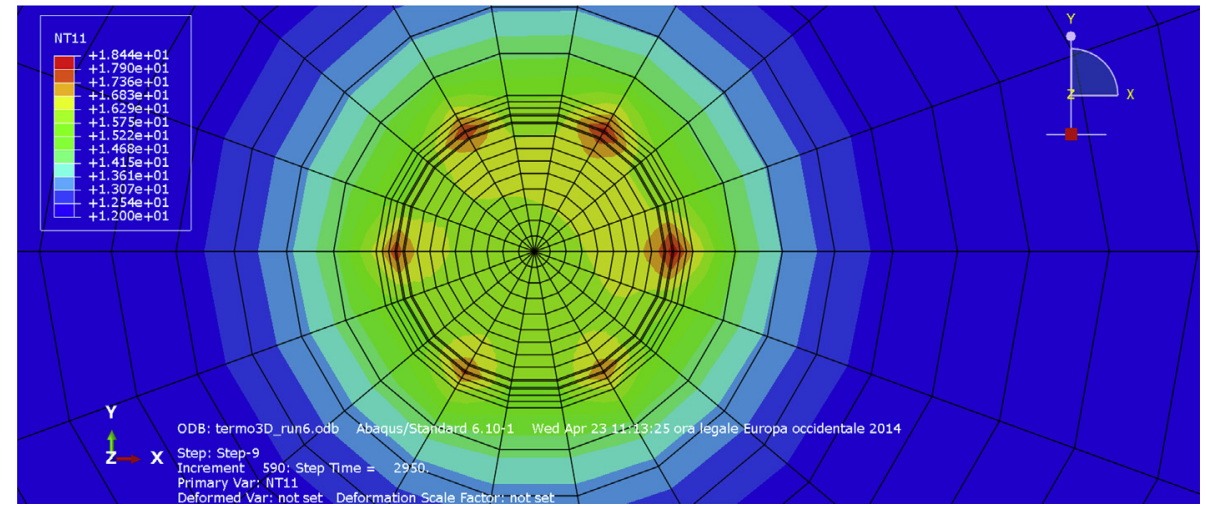

Fig. 14. Temperature contours on a cross-section along a $1000 \mathrm{~mm}$ diameter pile for run $\# 6$ of Table 5 , at the time instant $\mathrm{t}=590 \mathrm{~min}$ during the simulation.

that the amount of temperature change along the pipe is weakly inversely proportional to fluid velocity:

$\Delta T_{\text {flow }, k}=\frac{h_{e}\left(T_{s}-T_{f}\right) S}{\rho v A c_{p f}} \propto \frac{1}{v^{0.2}}$

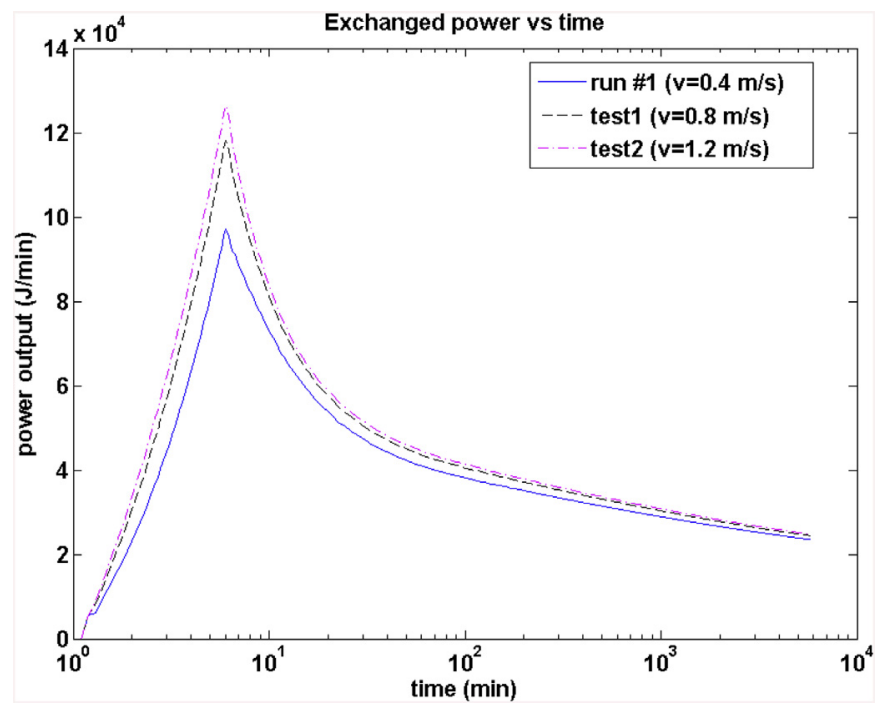

Fig. 15. Exchanged power vs time for three simulations where parameter settings differ only for the fluid velocity value. A weak proportionality of exchanged power with velocity can be noticed. Time is shown in logarithmic scale.
At the same time, $v$ also features in Equation (6) (via the mass flowrate), thus compensating for the inverse proportionality effect shown above, yielding a weak proportionality of exchanged power with velocity as shown in Fig. 15, where $v$ was set to $0.4,0.8$ and $1.2 \mathrm{~m} / \mathrm{s}$ while keeping the other settings as in run \#1 of Table 5 .

\section{Conclusions}

It is important to improve the energy efficiency of pile heat exchangers, so called energy piles, to reduce the pay back periods and thus increase the take up of this renewable heating technology. This study developed and validated an innovative numerical model that captures all of the key heat transfer phenomena, and applied it to this problem via Taguchi parametric analysis to determine the relative importance of various design parameters for achieving maximum exchanged energy. The results of the study mainly showed that:

1. Maximising the total pipe surface area available for heat transfer is the most important factor for increased energy efficiency. Therefore ensuring opportunities to install increased numbers of pipes within a pile cross section is recommended, although it should be noted that there are diminishing returns in terms of energy at very close pipe spacing. Longer pile lengths are also beneficial for energy exchange, but unlike borehole heat exchangers, this is not typically controlled by the geothermal design for energy piles.

2. Maximising the concrete thermal conductivity will also result in greater energy exchange. Practically this may not be straightforward as aggregate type, which has a strong influence on 
thermal conductivity, is typically defined by local availability. However, specification of the minimum required concrete additives, which can be detrimental to thermal properties, should be encouraged.

3. Contrary to general expectation, increasing the heat transfer fluid velocity does not have a significant impact on the overall exchanged energy, providing turbulent flow is maintained.

The model hereby presented is also intended to serve as a basis for further developments, as it is suitable for application to other types of energy geo-structures (such as diaphragm walls and tunnel linings) and for a number of different uses, such as aiding thermal parameter estimation during thermal response tests, and including other important coupled phenomena like thermo-mechanical effects, i.e. to explore any effects of the induced temperature variations in the pile mechanical behaviour.

\section{Acknowledgements}

The first author acknowledges financial support from European Union FP7 project under contract number PIAPP-GA-2013-609758HOTBRICKS.

The second author is funded by the Royal Academy of Engineering under their Research Fellow scheme.

\section{References}

[1] Amis T, Loveridge F. Energy piles and other thermal foundations, developments in UK practice and research. REHVA J 2014;2014(01):32-5.

[2] Banks D. An introduction to thermogeology: ground source heating and cooling. 2nd ed. Chichester, UK: Wiley- Blackwell; 2012.

[3] Bell FG. Engineering properties of soils and rocks. 4th ed. Blackwell Science; 2000.

[4] Bozis D, Papakostas K, Kyriakis N. On the evaluation of design parameters effects on the heat transfer efficiency of energy piles. Energy Build 2011;43(4): 1020-9.

[5] Brandl H. Energy foundations and other thermo-active ground structures. Geotechnique 2006;56(2):81-122.

[6] Carslaw HS, Jaeger JC. Conduction of heat in solids. 2nd ed. Oxford University Press; 1959.

[7] Choi JC, Lee SR, Lee DS. Numerical simulation of vertical ground heat exchangers: intermittent operation in unsaturated soil conditions. Comput Geotechnics 2011;38:949-58.

[8] Cecinato F. Mechanics of catastrophic landslides. Saarbrücken: Lambert Academic Publishing; 2011

[9] Cecinato F, Zervos A. Influence of thermomechanics in the catastrophic collapse of planar landslides. Can Geotechnical J 2012;49:207-25. http:// dx.doi.org/10.1139/T11-095.

[10] Clarke BG, Agab A, Nicholson D. Model specification to determine thermal conductivity of soils. Proc ICE, Geotechnical Eng 2008;161(GE3):161-8.
[11] Demirboga. Thermal conductivity and compressive strength of concrete incorporation with mineral admixtures. Build Environ 2007:42(7):2467-71.

[12] Diao NR, Zeng HY, Fang ZH. Improvements in modelling of heat transfer in vertical ground heat exchangers. HVAC\&R Res 2004;10(4):459-70.

[13] Fan R, Jiang Y, Yao Y, Ma Z. Theoretical study on the performance of an integrated ground source heat pump system in a whole year. Energy 2008;33: $1671-9$.

[14] Dupray F, Laloui L, Kazangba A. Numerical analysis of seasonal heat storage in an energy pile foundation. Comput Geotechnics 2014;55:67-77.

[15] Fillion M-H, Cote J, Konrad J-M. Thermal radiation and conduction properties of materials ranging from sand to rock-fill. Can Geotechnical J 2011;48: $532-42$.

[16] Gao J, Zhang X, Liu J, Li K, Yang J. Numerical and experimental assessment of thermal performance of vertical energy piles: an application. Appl Energy 2008;85:901-10

[17] GSHPA. Thermal pile design, installation and materials standard. Milton Keynes, UK: Ground Source Heat Pump Association; October 2012.

[18] Knellwolf C, Péron H, Laloui L. Geotechnical analysis of heat exchanger piles. J Geotech Geoenviron Eng (ASCE) 2011;137(10):890-902.

[19] Loveridge F, Powrie W, Nicholson D. Comparison of two different models for pile thermal response test interpretation. Acta Geotec 2014;9(3):367-84.

[20] Loveridge F, Powrie W. On the thermal resistance of pile heat exchangers. Geothermics 2014;50:122-35.

[21] Loveridge F, Powrie W. Temperature response functions (G-functions) for single pile heat exchangers. Energy 2013;57:554-64.

[22] McAdams WH. Heat transmission. 2nd ed. New York: McGraw-Hill; 1942.

[23] Neville AM. Properties of concrete. 4th ed. Longman; 1995.

[24] Park H, Lee S-R, Yoon S, Shin H, Lee D-S. Case study of heat transfer behavior of helical ground heat exchanger. Energy Build 2012;53(2012):137-44.

[25] Peace GS. Taguchi methods: a hands-on approach. Reading, Mass: AddisonWesley; 1993.

[26] Rees SW, Adjali MH, Zhou Z, Davies M, Thomas HR. Ground heat transfer effects on thermal performance of earth contact structures. Renew Sustain Energy Rev 2000;4:213-65.

[27] SIA. Utilisation de lachaleur du sol par des ouvrages de foundation et de soutenement en beton, Guide pour la conception, la realisation et la maintenance. Swiss Society of Engineers and Architects; 2005. Documentation D 0190.

[28] Sinnathamby G, Gustavsson H, Korkiala-Tanttu L, Perez Cervera C. Numerical analysis of seasonal heat storage systems of alternative geothermal energy pile foundations. J Energy Eng 2014. http://dx.doi.org/10.1061/(ASCE) EY.1943-7897.0000236.

[29] Spitler JD. Editorial: ground-source heat pump system research - past, present, and future. HVAC\&R Res 2005;11(2):165-7.

[30] Taguchi G, El Sayed M, Hsaing C. Quality engineering and quality systems. New York: McGraw-Hill; 1989.

[31] Tatro SB. Thermal properties. In: Lamond J, Pielert J, editors. Significance of tests and properties of concrete and concrete making materials. Stokoie, IL: Portland CementAssociation; 2006

[32] Wood CJ, Liu H, Riffat SB. An investigation of the heat pump performance and ground temperature of a pile foundation heat exchanger system for a residential building. Energy 2010;35(12):3932-4940.

[33] Zanchini E, Lazzari S, Priarone A. Long-term performance of large borehole heat exchanger fields with unbalanced seasonal loads and groundwater flow. Energy 2012;38:66-77.

[34] Zarrella A, De Carli M, Galgaro A. Thermal performance of two types of energy foundation pile: helical pipe and triple U-tube. Appl Therm Eng 2013;61(2): $301-10$ 